Original Research Paper

\title{
Motivations for Remittances and Philanthropy - Lessons from a Qualitative Meta-Synthesis of Literature
}

\author{
${ }^{1}$ Sabith Khan and ${ }^{2}$ Daisha M. Merritt \\ ${ }^{1}$ California Lutheran University, USA \\ ${ }^{2}$ Academic Liaison Social Impact at Center for Social Justice and Innovation, UNC Chapel Hill, USA
}

\author{
Article history \\ Received: 15-10-2017 \\ Revised: 24-01-2018 \\ Accepted: 3-03-2018 \\ Corresponding Author \\ Sabith Khan \\ California Lutheran University, \\ USA \\ Email: khanpgg@vt.edu
}

\begin{abstract}
Why do people send remittances? Also, what are the motivations for diaspora philanthropy? While each of these questions have been addressed by scholars in different way - with the most influential theories suggesting that 'identification' is the key theme that explains each of these phenomenon, we contend that there is much more than purely 'identification' with the recipients that is at play. In this study, based on synthesis of various theories and some empirical studies, we propose a new 'mid-range' theory, that seeks to explain the motivations for giving - both remittances and philanthropy. We explain how the motivations in each can be similar and distinct and offer insights that aim to further the scholarship on philanthropy and remittances. We hope to contribute to the discussion on the motivations for remittances and philanthropy and how it plays out, in the context of international development. With the urgency in fund-raising efforts and the need to accurately identify mechanisms and tools that will address the urgent needs of millions of people around the world, scholars are also coming together with innovative approaches and models to help understand how and why people give money. In addition, there is also the factor of donor fatigue that one has to contend with.
\end{abstract}

Keywords: Remittances, Philanthropy, Diaspora, USA, India, Kenya, China, Mexico

\section{Introduction}

The discourse of giving has encompassed that of remittances, in the recent past. With an increase in the attention on international and forced migration especially the ongoing refugee crisis impacting the Middle East and Europe and the flow of undocumented children from Central Europe into the U.S., there has been a renewed attention on remittances and philanthropic support. According to estimates from the World Bank, the amount of remittances sent to countries of origin are three times the total global international development aid (http://www.ted.com/talks/dilip_ratha_the_hidden_forc e_in_global_economics_sending_money_home?languag $\mathrm{e}=$ en\#t-97375).

Why do people send remittances? What are the motivations for diaspora philanthropy? While each of these questions have been addressed by scholars in multiple ways - with the most influential theories suggesting that 'identification' is the key theme that explains each of these phenomenon, we contend that there is much more than purely 'identification' with the recipients that is at play. In this study, based on synthesis of various theories and some empirical studies, we propose a new 'mid-range' theory, that seeks to explain the motivations for giving - both remittances and philanthropy. We explain how the motivations in each can be similar and distinct and offer insights that aims to further the scholarship on philanthropy and remittances.

We contribute to the discussion on the motivations for remittances and philanthropy and how it plays out, in the context of international development. With the urgency in fund-raising efforts and the need to accurately identify mechanisms and tools that will address the urgent needs of millions of people around the world, scholars are also coming together with innovative approaches and models to help understand how and why people give money. In addition, there is also the factor of donor fatigue that one has to contend with. Our central argument for this paper is that the concepts of 'remittances', 'philanthropy' and 'aid' are often conflated. While there are a lot of similarities between the three ideas and concepts, they are distinct and have their own underlying assumptions that take us in a 
different field of inquiry. We aim to nuance this debate and point to the need for such a distinction and differentiation, so our study of each of these phenomena can be better guided.

While there have been many scholarly and popular books on the importance of international aid (and its criticism), one of the most salient, that has had a big impact is William Easterly's The White Man's Burden (2006), where Easterly argues that despite the best efforts of Western nations to offer aid and technical expertise to the 'developing world', things have not gotten better. Despite some successes, the picture is quite bleak; he argues and suggests that ineptitude and lack of accountability are at the root of most problems - both in the developed and developing world. Easterly's is an anti-establishment voice; but one that has been finding resonance among scholars who are taking critical approaches to development aid, especially that involving transfer of money and technology.

Humanitarian aid, on the other hand, does not elicit the same sort of criticism; given that it is given in emergencies. However, any long-term dependency is what seems to be the focus of criticism, from many scholars; who seek to overcome the dependency cycle, which many nations and communities come fall into. Easterly's suggestion is that the more entrepreneurial or 'searchers' should conduct any sort of development; not centralized planners or bureaucrats from development agencies such as the World Bank or USAID or others, who do not understand the context or the nuances in culture; in the target countries.

As Easterly's book reminds us, the discourse on aid dismisses or negates the horizontal or peer-to-peer help that exists in many societies. This discourse also assumes that massive influx of money can solve most, if not all problems; while acknowledging that 'fixing the systems' of governance is necessary.

On the other spectrum is Jeffery D Sach's, The End of Poverty (2005). His framework is based on planning and intervention from the state, multilateral agencies such as the World Bank, IMF etc. His call is for using aid and interventions of various sorts to help with building infrastructure, better health systems etc. all the while ensuring that the end of poverty is near.

Scholars, such as the British researcher Jane Pollard (2006), whose research on Somalis in the U.K. points to the strong bonds of financial solidarity among the immigrant population. Her research has used the framework of 'resilience' to study how despite crushing poverty, many of these poor give about one-third of money in 'charity' to others - both in the U.K. and in Somalia.

We are focused on building from and examining such research; that goes beyond the structural approaches to understanding aid, remittances and philanthropy. Our primary research objective is to examine, in a comprehensive manner - and to synthesize - how people find motivations to give, despite being in precarious situations.

We suggest a new innovative analysis style approach that allows us a novel and creative ways of conceptualizing remittances and philanthropy - by going beyond the binaries that characterize the study of such phenomenon. The binaries of 'dependent' 'donor' are far too black and white and need to be nuanced and examples of horizontal giving, just pointed above showcase one such possibility. There are many such examples and cases where we are forced to re-look at our assumptions regarding philanthropy and development aid.

\section{Theory}

\section{The Boundaries of Philanthropy}

In his famous definition, Payton (1988) defines philanthropy as "voluntary action for the common good". To ask what should be considered as philanthropy and what should not be, Payton (1988: 27) adds that this question "also raises questions of values". Philanthropy is based on the pillars of compassion and community, he argues.

Schuyt (2013) proposes that for an act to be philanthropic, both the goal and the motivation must be primarily to benefit the common good. Discussing how classic definitions miss most forms of ethnic philanthropy, he formulates a definition for informal philanthropy besides formal philanthropy: "Making contributions, outside one's family, to other members of one's ethnic group and/or to organizations, for example of a religious or ethnic nature, without any apparent expectation of an economic return" (Schuyt, 2013: 26).

Many forms of diaspora giving do not fall in Schuyt's definition of informal philanthropy, because they are directed at family members. However, only looking at the beneficiaries of giving would surpass the intrinsic value of philanthropic giving. Both Payton and Schuyt emphasize the importance of other-oriented motivations as a part of what should be considered as philanthropy.

Therefore, we shift our attention to motivations. To what extent can we apply behavioral theories of philanthropic giving to remittances giving?

\section{The Identification Model}

There are many mechanisms that drive philanthropic giving (Bekkers and Wiepking, 2011). One of the major theoretical approaches to philanthropic giving is the 'identification model' as developed by Schervish and Havens (1997). Philanthropic giving, they argue, is fundamentally based on the idea that morality reaches beyond one's self. To be able to operationalize the factors that drive this morality, they propose five broad variables that drive giving. Communities of participation are the actual relationships one has; frameworks of consciousness refer to one's beliefs and values; direct 
requests directly evoke charitable contributions; models and experiences from one's youth shape philanthropic behavior in later life; discretionary resources are the objective and perceived resources which foster giving.

Below, we discuss the possible similarities and differences between philanthropic giving and remittances giving for each of those five factors.

\section{Communities of Participation}

The identification model states that the formal and informal relationships one has - in families, neighborhoods, schools, organizations etc. - is the basis for philanthropic behavior. Diaspora giving is international by nature. In the host country, immigrants can be involved in ethnic organizations or informal groups around ethnic origin which connect them to their home country. In the home country, migrants often have family and friends whom they contact and visit. Remittances are often hypothesized to decrease in time after the moment of migrating, although the evidence is mixed (Bettin and Lucchetti, 2012; Menjívar et al., 1998; Pozo and Amuedo-Dorantes, 2006; Lucas and Stark, 1985).

\section{Frameworks of Consciousness}

Beliefs and values are core to philanthropic giving. With regard to remittances giving, too, shared values can play an important role. Among diaspora, there can be a strong sense of belonging with the shared culture (Brinkerhoff, 2014). Furthermore, religion is strongly associated with remittances giving in many contexts (Kelly and Solomon, 2009).

\section{Direct Requests}

On first sight, remittances giving seems to be less dominated by fundraising than formal philanthropy. However, there can be direct requests from people in need or fundraising in ethnic associations in the host country.

\section{Models and Experiences from One's Youth}

Especially when it comes to labor migration, it is often the male who moves to another place and sends money to parents, partner, children and friends. In such situations, there is a direct link between giving and the experiences in one's early life.

\section{Discretionary Resources}

The traditional view on philanthropic giving is that someone high on resources gives to someone with fewer resources. This perspective has been contested, since it ignores many forms of poor-to-poor giving (Schuyt, 2013). On the one hand, remittances often flow from labor migration, where the giver moves to a region with more economic opportunities. On the other hand, immigrants are often part of the most deprived people in society. In general, research seems to show that income is positively related at least with amounts remitted (e.g., Brown, 1997; Menjívar et al., 1998; Sinning, 2011).

\section{Motivations for Remittances}

There has been a wide debate in many strands of the academic literature on the motivations to give remittances. Motives that are often distinguished are altruistic, exchange, strategic, insurance and investment motives (Rapoport and Docquier, 2006).

Previous empirical studies are mostly case studies of a particular ethnic group in a particular country, which does not enable for generalizable conclusions. Previous literature reviews have focused on the outcomes of remittances (Adams, 2011; Page and Plaza, 2006) and/or review the macro- and micro-economic determinants, reviewing mostly studies that use survey data or financial statistics (Hagen-Zanker and Siegel, 2007; Rapoport and Docquier, 2006; Ruiz and Vargas-Silva, 2009; Russell, 1986). Those reviews have shed light on the quantitative evidence for different motivations of remittances that can be deducted from the available data.

However, given the large variety of research designs and research contexts in the literature on remittances, there is need for stronger theoretical ground to explain findings from quantitative and qualitative studies.

Our review takes a more in-depth approach. It reviews previous research not only to summarize previous findings, but also to compare them and to identify similarities, differences and gaps.

\section{Methodology}

Qualitative Meta-Synthesis (QMS) is utilized to explore the expanse of published knowledge in philanthropy, community development, motivation and diaspora communities. In order to approach the research objective in understanding the role(s) that motivations may [not] play in remittance giving from displaced, relocated, or diaspora communities, a structured qualitative methodology is employed. Utilization of QMS is new in the social sciences and has only been minimally studied through medical sciences and social justice pursuits.

\section{Methods}

Qualitative Meta-Synthesis (QMS) allows for the interpretation of ethnographies, particular to this study we based our analysis on diaspora communities located in the United States of America. Inclusion of Chinese, Indian, Muslim, African and Hispanic refugee demographic groups are considered through this research. QMS is a methodology that allows for interpretation of multiple primary data sources. These research studies are systematically read, reviewed and questionnaires are applied in order to collectively integrate as broad of a perspective as possible across all research studies (Finlaydon and Dickson, 2008). QMS 
was chosen as the methodological approach for this project to construct as well-rounded an understanding as possible and to reach a potential mid-range theory of remittance giving. QMS allows for information across multiple ethnographies to be compared and findings to be cross examined to reveal connections and a more comprehensive understanding of the information. Additionally, there are no limits to the disciplines being examined; QMS can be utilized across disciplines to understand social, political, psychological and economical concepts. In previous research, QMS has been seen in medical science studies (nursing in particular) and a development studies, though it has yet to find wide usage (Hollinger, 2011). QMS offers a platform of comparing primary studies that at first glance may not have any connection, while on a deeper, more focused analysis, similarities and connection can be determined. QMS methodology is an approach that allows for development of mid-range theories which for this project in particular is of significant value.

The QMS approach is structured and completed in multiple stages. The beginning of the research design for QMS is straightforward: Identifying sources. This is the same as in any research endeavor qualitative, quantitative, or mixed methods. During this collection of information stage, we were able to establish our research parameters and boundaries. As a team, we set goals for the research studies that we collected, questions were developed and a literature review completed. After completing the literature review, QMS methodology requires that a particular population be defined for the individual studies. As the primary focus of this endeavor is to focus on diaspora communities, this was our first parameter, followed closely by geographical constraints, limiting our sample to diaspora communities located in the United States of America. From there we further bound our study by looking at ethnographies that discussed groups of individuals versus the individual themselves. Once the population of the studies was determined, the next step in QMS is developing a questionnaire or assessment tool to apply to each research study. In this step of the process, the questionnaire was applied to each study individually, answer recorded and documented. Development of the questionnaire (Appendix A) took several iterations, prior to use in assessing each study. Finally, a five (5) part questionnaire was constructed that included the following sections: Donors, Activities of Donors, Motivations, Ties between Donor and Recipient, Historical Roots. After the questionnaire was established it was applied to each of the decided upon ethnographies.

\section{Diaspora Philanthropy and Equitable Development} in China and India (2004)

The text based off a May 2003 workshop offers varying perspectives on both Chinese American and Indian American communities. Significant emphasis is placed on the economic impact as well as the historical underpinnings of diaspora philanthropy to these nations. Though the text is singular, it offered a bifurcated developmental study approach to China and India's diaspora communities.

\section{Portrait of a Giving Community (2006)}

This book examines the giving behavior of the Pakistani-American community and the challenges to giving. Based on a national survey and focus groups, this is the most exhaustive study of Pakistani-American philanthropy, to date.

\section{The Gulen Movement: A Sociological Analysis of a Civic Movement Rooted in Moderate Islam (2010)}

This text discusses the foundation of the Gulen Movement through a sociology perspective. Interviews and first person encounters are methods utilized to convey the information while contextualizing the movement and the actions in a social and political environment.

\section{The Cross-Border Connection: Immigrants, Emigrants and Their Homelands (2015)}

In this book Waldinger aims to take an integrative approach towards migration. Migration is both a cause and a consequence and developments in the community 'here' cannot be seen as separate from developments 'there'. The examples and empirical work focuses mostly on Mexicans and other Latin-Americans in the United States.

\section{Renewing Islam through Service (2015)}

Renewing Islam by Service is a Christian theologian's take on Islamic charity, by way of an indepth examination of the Hizmet Movement's spiritual framework. He contextualizes the work of Hizmet movement as one based on seeking 'God's pleasure.' The book is an addition to the literature on inter-faith dialogue as well as the study of the Hizmet movement, by an expert in Theology. This book covers the U.S., Netherlands and Turkey and diaspora communities in each of these countries.

\section{The New African Diaspora in the United States (2016)}

While the Trans-Atlantic slave trade left the AfricanAmerican community with little family ties, more recent migration streams resulted in African diaspora with strong connections to (Pan-) African culture. This bundle provides a number of empirical studies on communities with African origins in the United States, with a chapter focusing on the remittances of second-generation Ghanaian-Americans.

In total, six (6) primary source research studies were utilized, spanning from 2004 to 2016 in publication, resulting in six completed questionnaires. The final stage 
of the multistage process is to have a conversation with these studies and synthesize each of the completed questionnaires. This stage is arguably the most important, most time consuming, as well as the most subjective part of the process. Ideally, the final stage allows for a synthesis or summation across all of the studies to result in some findings or recommendations. In particular to our research endeavor, we had a team of three (3) researchers, thereby we had the ability to have a three researcher review, which fits along with recommendations that QMS be subject to a team approach (Sandelowski and Barroso, 2007). Additionally, in order for the findings and/or recommendation to be pertinent or even relevant, results must be situated within a body of literature; this offers the methodology and concluding results a level of external validity.

Limitations to this approach include the nature of cross discipline research and the inclusion of multiple different academic areas of inquiry as well as theoretical foundations. This limitation can also be translated as a strength of the research, because of the inclusion of multiple perspectives and subject approaches. Though it should be noted by the sheer nature of this methodological approach, there is an inherent amount of subjectivity to the analysis which ultimately informs the recommendation results and theorizing.

Utilizing this qualitative method of data analysis, offers a unique approach to the development of a midrange theory of giving.

\section{Descriptive Analysis}

When working through the five-part questionnaire and determining the relationship that the Gulen Movement, Indian American communities and Chinese American communities, Ghanian and Mexican as well as Turkish communities have with the aforementioned categories, an organic conversation occurred that included parsing out the five different categories across the six different books to determine if there were some connections, or presence of themes.

\section{Who are the Donors?}

In the case of Hizmet/ Gulen movement, the donors are largely Turkish businessmen/professionals, with strong ties to the Turkish communities, around the globe. Hizmet, in a sense can be considered a trans-national movement; with branches in over 100 countries and run entirely on a voluntary basis, by volunteers. The activities cover 'dialogue' sessions or spiritual gatherings, that are meant to serve as gatherings for spiritual uplift.

Waldinger (2015) emphasizes that people are not only immigrants in the host country but also at the same time emigrants in the sending country. Migration is both a cause and a consequence and developments in the community 'here' cannot be seen as separate from developments 'there'. His empirical work mostly focuses on immigrants from Mexico and other Latin-American countries.

Another migration stream that is covered in the empirical studies as covered in this meta-synthesis comes from African countries. Focusing on first- but also secondand third-generation migrants from West-African countries, different authors show that many kin ties exist between African countries and the United States.

\section{Activities of Donors}

Migrating might be seen as 'voting with your feet', which evokes strong feelings in the family, the community and the society, both in the host and the home countries. Although it is often perceived as an economic activity, sending money home is often part of an expression of one's identity. Many of the money flows seem to be informal, but there is also more formalized giving through hometown associations or other organizations, which might be labeled 'collective remittances'.

Remittances' giving is not without controversies. For example, donors are afraid that their money does not end up where it is most needed. Central-American immigrants in the United States have experienced large problems with proper identification, which also made it difficult to send money through accounts at American banks, which often requires official identification. Both the Mexican government and US banks lobbied to get the semi-official 'matrícula consular' increasingly accepted throughout the US (Waldinger, 2015). This example shows the large economic and political interests that are often associated with remittances.

There are also allegations related to Gulen movement, that have become acute; given the coup of July 15 th. While both of the chosen books related to the Gülen movement (Ebaugh, 2009) touch upon the controversies that surround the movement, it is fair to say that many of these have been unfounded - given that no court - other than the ones in Turkey have taken any action against the volunteering of the movement.

\section{Motivations}

A classic view in the literature on remittances is that they are largely economically motivated. This is partly confirmed by our findings, with migrants often being in a position with the resources to share. However, motivations are also political, religious and altruistic.

Islamism (the political ideal of trying to establish Islamic values in the public sphere) and Islamic ethics are key areas of interest that further speak to the larger issue of political idealism. In this book, Valkenberg pivots to the idea of 'Islamic ethics' as being at the core of the work that Hizmet does and not 'Islamism' which is a purely ideological and political movement that emerged, rather recently. Their philanthropy, volunteering and remittances are driven through religious motives - and there is enough scope for such an interpretation, given 
that charity is one of the five pillars of Islam.

In the case of the Pakistani community, the motives to give are largely for development. Given that remittances to Pakistan have been impacted in the post 9/11 scrutiny of money going into Pakistan from the U.S. and other western countries, there has been a shift in the patterns of giving. One can argue, based on the points made in the book that many Pakistanis want to contribute to the development projects 'back home' but are reluctant to do so, because of the lack of accountability of many of the organizations.

Both India and China see philanthropy as a way to connect back to your home and to help elevate the station of your family. Gender based philanthropic motivations as seen through one's individual identification is prevalent in India, especially via wealthy female donors. In China motivations related to one's identity are not as strong based on gender identification rather on organizational alignment.

Central-American immigrants might have, beside the economic motivations to support one's family, political purposes to send money, as giving might be used to exercise political influence. Waldinger (2015) describes how immigrants may become politically socialized in the United States. Combined with their remaining crossborder connections and their (sometimes rapidly) increasing resources, this can make them important players in local politics in their region of origin.

External motivations to give include policy incentives by home country governments. Family members may ask for - or expect - money to be sent and many (religious) communities have strong internal norms. Overall, however, peer pressure is not mentioned as a strong motivation for remittances giving in the six books in our sample.

\section{Ties Between Donor and Recipient}

By far the largest part of remittances is between family members. The results of fieldwork on Ghanaian-Americans show that the mere existence of a family tie often simply predicts whether second-generation immigrants give or not. This is not the whole story, though. Having a self-described Ghanaian-American, rather than a more general AfricanAmerican identity, correlates with sending remittances. This points at more complex processes beyond kin ties. Among some African diaspora, the idea of 'Pan-Africanism' defines values and decisions.

Again, it is emphasized that developments in the United States cannot be seen as separate from developments abroad.

The ties between the donors and recipients are one of self-defined 'brotherhood' in Islam and humanity - as the followers of Gulen movement see themselves as belonging to the larger humanity and identify others as part of this shared brotherhood; though they approach it through the lens of Islam.

China has five main avenues of giving based on membership affiliations: Academic, length of stay in country, nongovernmental organizations, traditional Chinatown groups and groups organized after PRC (1970s). In both cases (India and China) relationships between the diaspora communities' new home and the country of origin play a major role in the willingness to give.

\section{Historical Roots}

Historically, there has been a great increase in the number of Pakistanis in the U.S. post 1965, Hart-Cellar Act, which opened up migration to the U.S. from Asia and Middle East and did away with the race based restrictions on migration. Continuing ties with Pakistan are also another big factor, as are other professional associations that exist in the U.S. - like the Medical doctor's association and others, that continually rally Pakistanis to 'do good.'

Looking at the Indian and Chinese communities as laid out in the 2004 book from the Asia Center at Harvard, there is a constant stream of discussion around history and the strong role that traditions and the country's socio-political atmosphere plays in philanthropic giving. Both India and China have established [current] policies in place to increase direct trade, investment and especially technology focused diaspora giving.

After the Trans-Atlantic slavery trade, the AfricanAmerican community had little family ties left. More recent migration streams resulted in African diaspora with strong connections to (Pan-) African culture (Falola and Oyebade, 2016).

Migration streams from Central-America to the United States have been growing for decades, but Waldinger (2015) does not pay much attention to migration history.

Legal and political struggles that communities face include migration control measures that make family reunification more and more difficult. Also, dual citizenship is not allowed in many countries.

\section{Towards a Middle-Ground Theory}

Our paper covers books that span several diaspora communities, as mentioned earlier. Turkish, Chinese, Mexican, Indian and Ghanaians are covered in the books that we have chosen. In addition, the 'host' countries for these diaspora area also quite varied. We argue that this mix of countries and population groups offers us a wide variability, while at the same time, helping us theorize with the key concepts in mind.

Robert Merton defined a 'mid-range theory' as one which lies in between the working hypothesis that one encounters in a day to day and the grand unifying theories that sociologists and other social scientists aim to develop, through their work (Merton, 1949). Even though mid-range theories involve abstractions, they are of the order that they can be incorporated into the research being carried out, so as to be tested; Merton 
reminds us. For this reason, we believe that mid-range theories are apt for our work of theorizing, given that grand, unifying theories of philanthropy do not exist and there is an urgent need to theorize this phenomenon that is becoming ubiquitous by the day. The theorizing also proceeds by taking into account an 'abductive reasoning' style, where there is a combination of both deductive and inductive reasoning, moving from the specific to the general and from the general to the specific (Flyvbjerg, 2001). This approach calls for 'phronesis' or practical wisdom, as Flyvbjerg calls it; in analyzing the phenomenon and reasoning towards understanding it, holistically. Phronesis in this sense is pragmatic, context dependent and variable. We suggest this is important also because there is a consideration of values involved; when we talk about philanthropy and aid, in an international context. Whether it is American exceptionalism, ties to family or emotional attachment to one's country of origin, the question of values is at play.

Here are some of the key elements of our theory, as we see it evolve from the analysis of the six books that we carried out.

\section{Philanthropy for 'Development'?}

There are some commonalities in the case of India and Chinese diaspora giving. For instance, in China, giving used to be associated with building a school or clinic, now there is a trend to give with purpose and strategy to bring the Modern China an openness and respect internationally. Money is still given to poorer regions, because of the thought that the money will go further and have greater impact there. It is the same with in-kind donations, especially teaching in rural vs urban.

In the case of India, there is a lack of quantitative data, though there are estimates available from the World Bank and other agencies, on the amount of giving. As the books we examined shows that most of the empirical evidence is anecdotal; mostly based on interviews of wealthy Indian Americans, with limited sampling. Giving via, direct individual checks to local establishments. Growing trend of institutional giving; facilitated by Indian NGOs. Some support of the Digital Divide, encouraging individuals to be entrepreneurs. The notion of sending money for more 'strategic' initiatives has become more fashionable; rather than just sending money for sustenance, as the books under examination show.

\section{Philanthropy and Remittances to Build Community?}

With the Gulen movement, which has of late, become controversial both within Turkey and abroad, due to allegations by the Turkish state that the Gulen movement's founder Fethullah Gulen was behind the July 15 th coup. But as the books under review point out, the version of Islam and Islamic philanthropy depicted among its followers shows one that adheres to 'Islamic ethics' rather than 'Islamism' or political activism among its donors/ actors. While there have been overlaps between the Gulen movement and the political establishment, the founder of the movement and its followers contend that they have never sought to subvert the political system, which is marked by strict secularism.

The phenomenon of 'building community' is seen to be at play among other diaspora communities as well, as they seek to build institutions in their adopted country and also focus on the development (educational, cultural or spiritual) of the next generation.

\section{Philanthropy Encouraging 'Dialogue' and 'Discourse of Democracy'?}

While the remittances to Mexico and India shares similar 'motives' in terms of helping family or even start some projects; the governments of both countries see this as a positive phenomenon that needs encouragement. Similarly, remittances to Africa are generally seen in a positive light, given that much of the focus from development agencies has, historically, been on Africa. With new development models and growth of technology, Africa, one can argue is being 'rediscovered' as a new market for not only goods and services; but also for 'strategic philanthropy.'

\section{Identification Still Important, but in a More Complex Way}

Identity, in the form of a hyphenated identitywhether it is Ghanaian-American, Indian-American, Chinese-American is important for any form of diaspora remittances or philanthropy. When thinking about the difference between remittances and philanthropy, identification is seen in both respects (Fig. 1), but there is ultimately a difference that emerged from the analysis. Without a conscious effort on part of the diaspora communities to engage in this form of identity creation, or the existence of pre-existing family ties, such giving does not occur; as the books demonstrate. Does the longing for one's identity become more, as one lives longer in a different country? This question can be answered, through using remittances and philanthropy as a metric. As our literature review has shown, there is mixed proof that giving decreases over a period of time. On the other hand, the process of 'identification' or the process of creating a new identity - in the adopted 'home' - and its impact on remittances and philanthropy has not been theorized much. We suggest, based on our analysis and our own research that perhaps 'identification' is a continuum; that expands and contracts over a period of time - and is extremely contextual. For instance, during times of crisis (such as a humanitarian disaster), the identification with one's own kin and people of one's country of origin goes up. There is reason to believe this is the case, as people 
give to causes that they identify with - from this framework - rather than to other causes. In the research of one of the researchers, he has seen this phenomenon playing out in more than one case.

\section{Conclusion}

To sum up, the idea of identification is key to understanding each of the ideas under discussion here philanthropy and remittances (Fig. 1). While the process of identity formation has been extensively studied by anthropologists and sociologists, we have seen that the process of identification, as it plays out in the field of philanthropic contributions and how it impacts or is impacted by philanthropy has not been studied as much.

It is the conclusion of this research that there is a hierarchy of motivations when thought through the concepts of remittances and philanthropy (Fig. 2). These tiers or levels of motivation include Giving to build community as a foundational step that crosses all cultural populations reviewed. Followed by Giving to support 'resilience' of groups and finally Giving for ethnic solidarity. These reasons for giving or motivations were clearly discovered through the primary sources and understood across all immigrant/ refugee groups.

Our paper has tried to nuance the arguments made by several scholars and to synthesize some of their key ideas, to form a more holistic framework to understand each of the processes on their own terms (Fig. 2). While Schervish and Havens (1997) have argued for operationalizing the factors that drive this morality, by proposing five broad variables that drive giving, one cannot ignore the role that changing identities or multiple identities or identities in flux can impact the way that people find their own 'community'. This is particularly important, given the role that changing citizenship, identity or community? While theorists have proposed ideas such as a human community with no claim to identity, such as in the work of Giorgio Agamben, in his classic 'The Coming community,' (1990), the work of Schervish and Havens (1997) and other Sociologists is on the opposite spectrum, where they argue that people primarily claim their 'belongingness' through their identity. A belongingness that is agnostic of identity may be a theoretical possibility, but not a practical reality; they contend.

Stuart Hall's conception of identity as something of a 'process' and not fixed in time may be a better analytical framework to understand the phenomenon at hand (Hall, 2000). His argument that one needs to go beyond one's ethnocentrism to define 'identity' whether it is Europeanness or Americanness is more urgent than ever. Given the massive flow of people, ideas and money; given the refugee crisis that we are witnessing; along with other catalysts, for remittances and philanthropic giving, there is an urgent need to nuance this debate around identity and identification. Going beyond binaries, acknowledging the full validity of hyphenated identities such as SomaliAmerican, Chinese American etc. is not only a crucial part of this process, but an important element in how we frame and understand 'philanthropy' and 'remittances.' Moving beyond fixed categorization of ideas and persons may be a first step in this process.
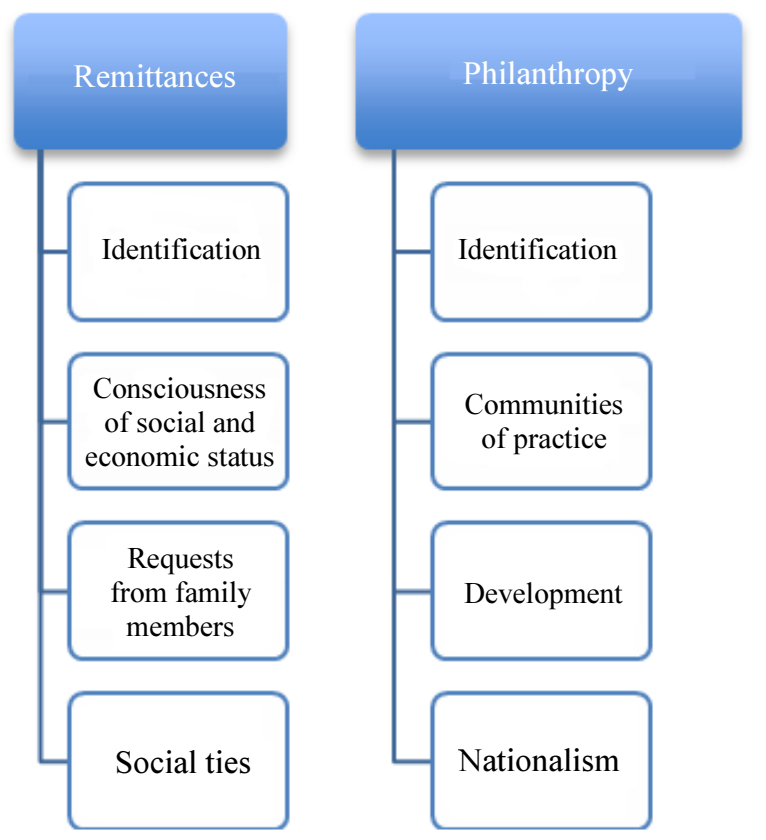

Fig. 1: Remittances and philanthropy, similarities in hierarchy of motivations

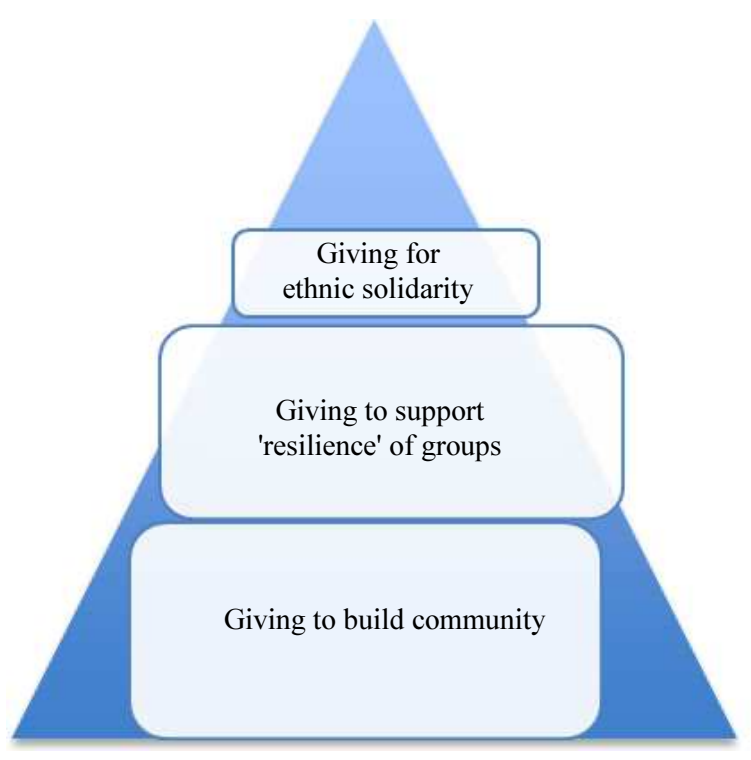

Fig. 2: Hierarchy of motivations- Remittances and philanthropy 


\section{Implications for Theory}

The insights and arguments presented in these sixbook challenge us to reconsider the notion that remittances to family cannot be considered as 'philanthropy.' While there is empirical proof that families that benefit from remittances have a better standard of living and are able to send their kids to school, more often than those that don't receive these remittances. How is this not 'philanthropy' if in the long run; these remittances translate into a 'public good' of having a more educated town/ village? The positive externalities of these private acts, which are often driven by kinship behavior, we believe, force us to reconsider these binaries. While we are not making the claim that remittances and philanthropy are the same and that these two categories should be collapsed; we are arguing for a closer reexamination of these two phenomenons - as we have attempted - in an effort to look for common ground, rather than points of differences (refer again to Fig. 1).

When comparing explanations for remittances giving with the identification model for charitable giving Schervish and Havens (1997), all five explaining factors (communities of participation, frameworks of consciousness, direct requests, models and experiences from one's youth and discretionary resources) can be recognized in the literature on remittances giving. However, there are at least two features of diaspora giving that makes it different from philanthropic giving as it is traditionally understood. First, instead of the traditional dependency relationship between donor and recipient, remittances are often poor-to-poor giving. Second, most migrants do not have a single identity, but rather a 'hyphenated identity' that cannot be understood in a single variable. Our analyses show that remittances are a multi-faceted phenomenon driven by a combination of economic, cultural, social, religious and political motivations and surrounded by pressures from governments, religious organizations and financial institutions.

Another example of such remittances, that we haven't included in our study, but one that bears mention is that of Jane Pollard's framing of the Somali's philanthropy in London as 'resilience'. Her framing is another theoretical attempt at making sense of the charity that occurs among the most vulnerable and poor; who are on welfare themselves.

Finally, as we wrap up our arguments, it is important to remember that the field of philanthropy, international aid, remittances needs a broader range of methods. While positivist methods and reliance on numbers can tell us part of the story, we suggest that we need more pragmatic, intimate and closer look at the stories of giving, aid and remittances, which incorporate a more qualitative methodology. Perhaps Merton and Flyvbjerg reminders to focus on the pragmatic, mid-range aspects of data are key to our better understanding of each of these phenomenons (Flyvbjerg, 2001; Merton, 1949).
While we believe that positivist methods are a key and integral part of research efforts, more synthesis or mixed methods of research can yield richer results, as well.

Should we use frameworks of 'resilience' or 'solidarity' more than purely use categories of 'remittances' and 'philanthropy' in describing these sorts of giving behavior? Our synthesis of arguments from these books seems to suggest that perhaps being sensitive to these categories, when we discuss remittances and philanthropy will certainly be helpful and nuance the arguments, as we formulate them.

\section{Acknowledgement}

We would like to acknowledge Dr.Joyce Rothschild for introducing us to this methodology.

\section{Author's Contributions}

Sabith Khan: Writing, conceptualization, design. Daisha M. Merritt: Conceptualization, design, editing, writing.

\section{Ethics}

The authors did not receive any funding for this project and report no conflict of interest.

\section{References}

Adams, R.H., 2011. Evaluating the economic impact of international remittances on developing countries using household surveys: A literature review. J. Dev. Stud., 47: 809-828.

Bekkers, R. and P. Wiepking, 2011. A literature review of empirical studies of philanthropy. Eight mechanisms that drive charitable giving. NVSQ, 40: 924-973.

Bettin, G. and R. Lucchetti, 2012. Intertemporal remittance behaviour by immigrants in Germany. SOEPpapers.

Brinkerhoff, J.M., 2014. Diaspora philanthropy: Lessons from a demographic analysis of the Coptic Diaspora. Nonprofit Voluntary Sector Quart., 43: 969-992.

Brown, R.P., 1997. Estimating remittance functions for Pacific Island migrants. World Dev., 25: 613-626.

Ebaugh, H.R., 2009. The Gülen movement: A sociological analysis of a civic movement rooted in moderate Islam. Springer Science and Business Media.

Falola, T. and A. Oyebade, 2016. The New African Diaspora in the United States. 1st Edn., Routledge, New York.

Finlaydon and Dickson, 2008. Qualitative Metasynthesis: A guide for the novice. NCBI. Nurse Res., 15: 59-71. 
Flyvbjerg, B., 2001. Making social science matter. UNESCO Report.

Hagen-Zanker, J. and M. Siegel, 2007. The determinants of remittances: A review of the literature.

Hall, S., 2000. Who needs identity? From du Gay and Evans J and Redman, P. Identity: A Reader. Sage. DOI: $10.4135 / 9781446221907 . n 1$

Hollinger, K., 2011. Alternative Pathways to Peace and Development in Rural Chiapas. Mexico. Diss. Virginia Tech.

Kelly, C.S. and B. Solomon, 2011. The influence of religion on remittances sent to relatives and friends back home. J. Bus. Econom. Res.

Lucas, R.E. and O. Stark, 1985. Motivations to remit: Evidence from Botswana. J. Political Economy.

Menjívar, C., J. DaVanzo, L. Greenwell and R.B. Valdez, 1998. Remittance behavior among Slavadorian and Filipino Immigrants in Los Angeles. Int. Migration Rev., 32: 97-126.

Merton, R., 1949. On Sociological Theories of the Midrange. Blackswell Publishing.

Page, J. and S. Plaza, 2006. Migration remittances and development: A review of global evidence. J. African Econom., 15: 245-336.

Payton, R.L., 1988. Philanthropy: Voluntary Action for the Public Good. 1st Edn., American Council on Education/Macmillan Publishing Company, New York, ISBN-10: 002896490X, pp: 282.

Pozo, S. and C. Amuedo-Dorantes, 2006. The time pattern of remittances: Evidence from Mexican migrants. Well-Being Soc. Policy, 2: 49-66.
Rapoport, H. and F. Docquier, 2006. The Economics of Migrants' Remittances. In: Handbook of the Economics of Giving, Altruism and Reciprocity, Kolm, S.C. and J.M. Ythier, (Eds.), Elsevier, Amsterdam, ISBN-10: 0080478212, pp: 1135-1198.

Russell, S.S., 1986. Remittances from international migration: A review in perspective. World Dev., 14: 677-696.

Ruiz, I. and C. Vargas-Silva, 2009. To send, or not to send: That is the question-a review of the literature on workers' remittances. J. Bus. Strategies, Forthcoming.

Sandelowski, M. and J. Barroso, 2007. Using Qualitative Metasummary to Synthesize Qualitative and Quantitative Descriptive Findings. NCBI. Res Nurs Health, 30: 99-111.

Schervish, P.G. and J.J. Havens, 1997. Social participation and charitable giving: A multivariate analysis. Voluntas: Int. J. Voluntary Nonprofit Organizations, 8: 235-260.

Schuyt, T., 2013. Philanthropy and the Philanthropy Sector: An Introduction. 1st Edn., Ashgate Publishing, Farnham, ISBN-10: 147241280X, pp: 158.

Sinning, M.G., 2011. Determinants of savings and remittances: Empirical evidence from immigrants to Germany. Rev. Econom. Household, 9: 45-67.

Waldinger, R., 2015. The Cross-Border Connection: Immigrants, Emigrants and Their Homelands. 1st Edn., Harvard University Press, Cambridge, ISBN-10: 0674736737, pp: 231. 